\title{
Evaluasi Rasionalitas Penggunaan Antihipertensi pada Pasien Geriatri di RSUD Dr. H Bob Bazar, SKM Lampung Selatan
}

\section{Rationality Evaluation of The Use of Antihypertensive in Geriatric Patient in Dr. H. Bob Bazar, SKM Public Hospital South Lampung}

\author{
Nenti Herawati ${ }^{1}$, Gusti Ayu Rai Saputri ${ }^{2^{*}}$, Angga Saputra Yasir ${ }^{3}$ \\ 1,2 Program Studi Farmasi, Fakultas Kedokteran, Universitas Malahayati Jalan Pramuka No 27 Kemiling Kota \\ Bandar Lampung, Lampung Indonesia \\ ${ }^{3}$ Institut Teknologi Sumatera Lampung Selatan, Lampung, Indonesia
}

*Corresponding author

Email: gustiayu340@gmail.com

Keyword :

Evaluation,

Hypertension,

Geriatric

Rationality,

\begin{abstract}
A b s t r a c t
Background: Hypertension is a condition characterized by an increase in blood pressure $>140 / 90 \mathrm{mmHg}$. Hypertension is an important risk factor for causing other cardiovascular diseases. Evaluation of the use of antihypertensive drugs aims to ensure the rational use of drugs in patients with hypertension. Objective: This study aims to determine the rationality of the use of antihypertensive drug in geriatric patients at RSUD Dr. H. Bob Bazar, SKM Lampung Selatan in terms of the correct diagnosis, the right indication, the right drug, the right dose, the right way of giving, the right time interval for giving and the right patient. Methods: This study is a non-experimental type of research in the sense that it does not provide any treatment to the research subjects and used retrospective data, namely medical record sheetsof hypertension patients in 2019. Of the total 423 medical records of hypertension patients, 51 medical records were used as research samples. The data obtained were then compared using the JNC VIII literature and the Geriatric Dosage Handbook (Lexicomp Drug Reference). Results: The results showed that the rationality of the use of antihypertensives in geriatric patients in RSUD Dr. H. Bob Bazar, SKM Lampung Selatan, is 100\% accurate on diagnosis, $100 \%$ right on indication, $100 \%$ right on drug, $94.12 \%$ right on dose, $100 \%$ right on route of administration, $96.08 \%$ right on time interval and $100 \%$ right on patient. Conclusion: The percentage value of rational used of antihypertensive drugs in geriatric patients is $96,8 \%$.
\end{abstract}


antihipertensi pada pasien geriatri adalah $98,6 \%$.

How To Cite : Herawati, N., Saputri, G.A.R., \& Yasir, A.S. 2021. Evaluasi Rasionalitas Penggunaan Antihipertensi pada Pasien Geriatri di RSUD Dr. H Bob Bazar, SKM Lampung Selatan. Journal of Islamic Medicine. 5(2),133-140 https://doi.org/10.18860/jim.v5i2.13435

Copyright $\left({ }^{\circ} 2021\right.$

\section{LATAR BELAKANG}

Hipertensi merupakan situasi yang paling umum berlangsung pada orang dewasa dibandingkan dengan persoalan kesehatan yang lainnya dan merupakan faktor risiko dari penyakit kardiovaskular. Dari keseluruhan negara-negara di dunia, penderita hipertensi pada negara-negara berpenghasilan tinggi (negara maju) memiliki prevalensi yang lebih rendah yaitu $35 \%$, sedangkan pada negara-negara berkembang prevalensi nya yaitu $40 \%{ }^{1}$

Berdasarkan Riskesdas 2018 menyebutkan bahwa prevalensi hipertensi yang terjadi di Indonesia pada usia $>18$ yaitu $34,1 \%$. Sedangkan berdasarkan diagnosis dokter tahun 2018 menurut karakteristik usia 18-24 sebesar 13,2\%, usia 25-34 sebesar $20,1 \%$, usia $35-44$ sebesar $31,6 \%$, usia $45-$ 54 sebesar 45,3\%, usia 55-64 sebesar $55,2 \%$, usia $65-74$ sebesar $63,25 \%$, dan usia $75+$ sebesar $69,5 \%{ }^{2}$. Dari data tersebut terlihat bahwa geriatri memiliki persentase prevalensi hipertensi tertinggi yang merupakan penyakit kardiovaskular risiko utama penyebab kematian tertinggi di Indonesia. ${ }^{3}$ Data dari laporan surveilans Dinkes Provinsi Lampung tahun 2018 prevalensi hipertensi di provinsi Lampung sudah mencapai $29,94 \%$ dan menduduki penyakit peringkat teratas dengan jumlah penderita yaitu 545.625 orang. Sedangkan hipertensi di Kabupaten Lampung Selatan menunjukkan pasien hipertensi pada lakilaki 8.079 dan pasien hipertensi pada perempuan mencapai 9.725 dengan mendapati Lamsel menjadi urutan pertama dengan pasien hipertensi terbanyak di provinsi Lampung.

RSUD Dr. H. Bob Bazar, SKM termasuk rumah sakit pemerintah dengan jumlah pasien hipertensi terbanyak kedua di poli umum pada tahun 2019. Seiring peningkatan kasus hipertensi maka penggunaan obat yang rasional merupakan elemen penting dalam tercapainya kualitas kesehatan serta perawatan medis bagi pasien sesuai standar yang diharapkan. Apabila penggunaan antihipertensi tidak rasional, maka akan mengurangi kepercayaan masyarakat kepada tenaga kesehatan; efek samping obat dan kesalahan pengobatan yang membahayakan tubuh dan membuang biaya yang tidak perlu. Oleh karena itu, tujuan penelitian ini adalah mengetahui bagaimana rasionalitas penggunaan antihipertensi pada geriatri di RSUD Dr. H. Bob Bazar, SKM periode Januari - Juni 2019 berdasarkan standar terapi utama menurut JNC VIII dan Geriatric Dosage Handbook (Lexicomp Drug Reference).

\section{METODE}

\begin{abstract}
Alat dan Bahan
Alat yang digunakan dalam penelitian ini, antara lain Literatur JNC VIII dan Geriatric Dosage Handbook (Lexicomp Drug Reference). Bahan penelitian yang digunakan adalah catatan rekam medik pasien geriatri penderita hipertensi
\end{abstract}

\section{Jenis Penelitian}

Penelitian ini merupakan penelitian analisis deskriptif dengan pengambilan data secara retrospektif yang didasarkan pada catatan medik.

\section{Populasi dan Sampel}

Populasi penelitian adalah semua catatan medik pasien hipertensi rawat jalan di RSUD Dr. H. Bob Bazar, SKM periode Januari sampai Juni 2019. Sampel dari penelitian ini ialah catatan medik terpilih dari populasi yang memenuhi kriteria penelitian. Jumlah sampel yang digunakan yaitu 51 data catatan medik. Teknik pengambilan sampel yang digunakan 
Evaluasi Rasionalitas Penggunaan Antihipertensi pada Pasien Geriatri di RSUD Dr. H Bob Bazar, SKM Lampung Selatan

dalam penelitian ini adalah teknik purposive sampling yang memenuhi kriteria inklusi.

\section{Pengambilan Data}

Sampel yang diambil meliputi data rekam medik yang sesuai dengan kriteria inklusi, yaitu:

a. Data rekam medik pasien geriatri yang terdiagnosis hipertensi tanpa komplikasi

b. Pasien geriatri yang mendapat pengobatan antihipertensi

c. Data rekam medik pasien hipertensi yang lengkap

Kriteria Eklusi :

a. Pasien geriatri yang didiagnosis hipertensi dengan komplikasi

b. Pasien geriatri yang didiagnosis hipertensi yang tidak menerima terapi antihipertensi.

c. Data rekam medik pasien hipertensi yang tidak lengkap.

\section{Pengolahan Data}

Tahap pengolahan data dilakukan dengan membandingkan data yang didapat dengan JNC VIII dan Geriatric Dosage Handbook (Lexicomp Drug Reference).

\section{Etik}

Metode dalam penelitian ini telah memenuhi kaji etik dari Komisi Etik Penelitian Kesehatan Universitas Malahayati dengan nomor surat Keterangan Kelaikan Etik 1582/EC/KEP-UNMAL/II/2021

\section{Analisis Data}

Data dianalisis secara deskriptif dengan menguraikan data rekam medis, untuk menggambarkan profil pasien hipertensi, kemudian hasil tersebut dianalisis berdasarkan pola penggunaan obat monoterapi dan kombinasi dan dievaluasi rasionalitasnya berdasarkan JNC VIII dan Geriatric Dosage Handbook (Lexicomp Drug Reference) sehingga persentase rasionalitas dapat diketahui.
$\%$ Ketepatan $=\frac{\text { Jumlah kasus yang tepat }}{\text { total } \text { kasus }} \times 100 \%$
1. $\frac{\text { Jumlah pasien tepat diagnosis }}{\text { jumlah seluruh kasus }} \times 100 \%$
2. $\frac{\text { Jumlah pasien tepat indikasi }}{\text { jumlah seluruh kasus }} \times 100 \%$
3. $\frac{\text { Jumlah pasien tepat obat }}{\text { jumlah seluruh kasus }} \times 100 \%$
4. $\frac{\text { Jumlah pasien tepat dosis }}{\text { jumlah seluruh kasus }} \times 100 \%$
5. $\frac{\text { Jumlah pasien tepat cara pemberian }}{\text { jumlah seluruh kasus }} \times 100 \%$
6. $\frac{\text { Jumlah pasien tepat interval waktu p }}{\text { jumlah seluruh kasus }} \times 100 \%$
7. $\frac{\text { Jumlah kasus pasien tepat pasien }}{\text { jumlah seluruh kasus }} \times 100 \%$

\section{HASIL PENELITIAN}

Tabel 1. Karakteristik Pasien Hipertensi di Instalasi Rawat Jalan RSUD Dr. H. Bob Bazar, SKM Periode Januari - Juni 2019

\begin{tabular}{clcc}
\hline No & \multicolumn{1}{c}{ Karakteristik } & Jumlah Pasien $(\mathbf{n}=\mathbf{5 1})$ & Persentase (\%) \\
\hline & Usia Pasien & & \\
1 & $60-69$ & 30 & 58,8 \\
2 & $70-79$ & 19 & 37,3 \\
3 & $80-89$ & 2 & 3,9 \\
& Total & 51 & 100 \\
\hline & Jenis Kelamin & & \\
1 & Laki-laki & 22 & 43,2 \\
2 & Perempuan & 29 & 56,8 \\
& Total & 51 & 100 \\
\hline & Tekanan Darah & & \\
1 & $\geq 140 / 90-159 / 99$ mmHg & 42 & 82,4 \\
2 & $\geq 160 / 100$ mmHg & 9 & 17,6 \\
& Total & 51 & 100 \\
\hline
\end{tabular}


Tabel 2. Pola Penggunaan Obat Antihipertensi pada Pasien Geriatri di Instalasi Rawat Jalan RSUD Dr. H. Bob Bazar, SKM Periode Januari - Juni 2019

\begin{tabular}{|c|c|c|c|c|c|}
\hline Klasifikasi Terapi & Nama Obat & BSO & Rute & Jumlah & $\%$ \\
\hline \multicolumn{6}{|l|}{ Terapi Tunggal } \\
\hline \multirow[t]{2}{*}{ ACEI } & Captopril & Tablet & Oral & 5 & 9,80 \\
\hline & Lisinopril & Tablet & Oral & 1 & 1,96 \\
\hline \multirow[t]{2}{*}{$\mathrm{ARB}$} & Candesartan & Tablet & Oral & 4 & 7,84 \\
\hline & Irbesartan & Tablet & Oral & 2 & 3,92 \\
\hline Beta Blocker & Bisoprolol & Tablet & Oral & 1 & 1,96 \\
\hline \multirow[t]{2}{*}{$\mathrm{CCB}$} & Amlodipin & Tablet & Oral & 7 & 13,73 \\
\hline & Nifedipin & Tablet & Oral & 1 & 1,96 \\
\hline \multicolumn{6}{|l|}{ Terapi 2 Kombinasi } \\
\hline \multirow{2}{*}{ Diuretik loop + ACEI } & Furosemid + Ramipril & Tablet & Oral & 1 & 1,96 \\
\hline & Furosemid + Lisinopril & Tablet & Oral & 1 & 1,96 \\
\hline \multirow[t]{2}{*}{ Diuretik tiazid + ACEI } & HCT + Enalapril & Tablet & Oral & 3 & 5,88 \\
\hline & HCT + Captopril & Tablet & Oral & 2 & 3,92 \\
\hline Diuretik loop + Beta Blocker & Furosemid + Propranolol & Tablet & Oral & 1 & 1,96 \\
\hline Diuretik loop $+\mathrm{CCB}$ & Furosemid + amlodipin & Tablet & Oral & 3 & 5,88 \\
\hline \multirow[t]{3}{*}{$\mathrm{CCB}+\mathrm{ACEI}$} & Amlodipin + Captopril & Tablet & Oral & 1 & 1,96 \\
\hline & Amlodipin + Lisinopril & Tablet & Oral & 2 & 3,92 \\
\hline & Nifedipin + Lisinopril & Tablet & Oral & 2 & 3,92 \\
\hline \multirow[t]{3}{*}{$\mathrm{CCB}+\mathrm{ARB}$} & Amlodipin+ Candesartan & Tablet & Oral & 5 & 9,80 \\
\hline & Amlodipin + Irbesartan & Tablet & Oral & 1 & 1,96 \\
\hline & Amlodipin + Valsartan & Tablet & Oral & 2 & 3,92 \\
\hline ACEI + Beta Blocker & Captopril + Bisoprolol & Tablet & Oral & 1 & 1,96 \\
\hline CCB + Beta Blocker & Amlodipin + Bisoprolol & Tablet & Oral & 1 & 1,96 \\
\hline ARB + Beta Blocker & Candesartan + Bisoprolol & Tablet & Oral & 1 & 1,96 \\
\hline Antagonis Aldosteron + CCB & Spironolakton + Amlodipin & Tablet & Oral & 1 & 1,96 \\
\hline \multicolumn{6}{|l|}{ Terapi 3 Kombinasi } \\
\hline & $\begin{array}{l}\text { Furosemid }+ \text { Spironolakton }+ \\
\text { Candesartan }\end{array}$ & Tablet & Oral & 1 & 1,96 \\
\hline & HCT+Ramipril + Amlodipin & Tablet & Oral & 1 & 1,96 \\
\hline Total & & & & 51 & 100 \\
\hline
\end{tabular}

Tabel 3. Rasionalitas Penggunaan Obat Antihipertensi yang digunakan pada Pasien Hipertensi di Instalasi Rawat Jalan RSUD Dr. H. Bob Bazar, SKM Periode Januari - Juni 2019

\begin{tabular}{|c|c|c|c|c|}
\hline \multirow{3}{*}{$\begin{array}{l}\text { Kriteria } \\
(\mathrm{n}=\mathbf{5 1})\end{array}$} & \multicolumn{4}{|c|}{$\begin{array}{l}\text { Rasionalitas Berdasarkan JNC VIII dan Geriatric } \\
\text { Dosage Handbook (Lexicomp Drug Reference) }\end{array}$} \\
\hline & \multicolumn{2}{|c|}{ Tepat } & \multicolumn{2}{|c|}{ Tidak Tepat } \\
\hline & Jumlah & Persentase $(\%)$ & Jumlah & Persentase $(\%)$ \\
\hline Tepat Diagnosis & 51 & 100 & 0 & 0 \\
\hline Tepat Indikasi & 51 & 100 & 0 & 0 \\
\hline Tepat Obat & 51 & 100 & 0 & 0 \\
\hline Tepat Dosis & 48 & 94,18 & 3 & 5,88 \\
\hline Tepat Cara Pemberian & 51 & 100 & 0 & 0 \\
\hline Tepat Interval Waktu Pemberian & 49 & 96,08 & 2 & 3,92 \\
\hline Tepat Pasien & 51 & 100 & 0 & 0 \\
\hline
\end{tabular}




\section{PEMBAHASAN}

\section{Karakteristik Pasien}

Karakteristik pasien dibedakan berdasarkan usia, jenis kelamin dan tekanan darah. Menurut data tesebut pasien hipertensi pada geriatri yang paling banyak adalah rentang usia 60-69 tahun. Sejalan dengan bertambahnya usia, terjadi perubahan struktur pada pembuluh darah besar, sehingga lumen bisa menjadi sempit dan pembuluh darah menjadi lebih kaku, sebagai akibatnya terjadi peningkatan tekanan darah sistolik. ${ }^{4}$

Kejadian hipertensi pada penelitian ini mayoritasnya adalah perempuan. Perempuan yang belum menopause lebih terlindung dari resiko penyakit kardiovaskular dibandingkan dengan perempuan yang telah mengalami menopause, karena memiliki hormon estrogen yang berperan dalam peningkatan kadar High Density Lipoprotein (HDL). Perempuan yang mengalami menopause akan mengalami penurunan hormon estrogen yang menyebabkan terjadinya penurunan kadar HDL. ${ }^{5}$

Berdasarkan karakteristik dari tingkatan hipertensi, mayoritas subjek penelitian ini yaitu hipertensi stage 1 sebesar $82,4 \%$. Pasien yang berusia $\geq 60$ tahun, 50 $60 \%$ mempunyai risiko hipertensi stage 1 dan 2 atau memiliki tekanan darah $\geq 140 / 90$ mmHg. Hal ini merupakan suatu dampak degenerasi terhadap orang yang lanjut usia. ${ }^{6}$

\section{Pola Penggunaan Obat Antihipertensi}

Berdasarkan Tabel 2 menunjukkan obat antihipertensi monoterapi yang paling sering digunakan pada periode Januari -Juni 2019 untuk pasien geriatri adalah golongan CCB yaitu amlodipin dengan jumlah pasien 7 dari 51 pasien $(13,72 \%)$. Obat antihipertensi CCB adalah obat antihipertensi yang paling banyak di berikan terutama amlodipin. Antihipertensi pilihan pertama untuk pasien lansia adalah golongan CCB. Dalam JNC VIII dijelaskan bahwa lini pertama untuk hipertensi pada geriatri yaitu
CCB dihydropyridine long-acting. Relaksasi jantung dan otot polos terjadi karena penggunaan CCB yang mengakibatkan terhambatnya saluran kalsium yang sensitif terhadap tegangan, sehingga masuknya kalsium ekstraseluler kedalam sel menjadi berkurang. Relaksasi otot vaskular menyebabkan vasodilatasi dan berhubungan dengan reduksi tekanan darah. ${ }^{7}$

Sedangkan dalam terapi kombinasi, amlodipin dan candesartan adalah yang paling banyak digunakan yaitu sebesar 9,80\%. Kombinasi tersebut merupakan kombinasi yang tepat karena keduanya bekerja dengan mekanisme yang berbeda dalam menurunkan tekanan darah. Salah satu golongan antihipertensi yang memiliki pengelolaan klinis hipertensi baik secara monoterapi maupun kombinasi yaitu golongan CCB yang telah terbukti aman dan efektif dalam penurunan tekanan darah dengan toleransi yang baik. ${ }^{8}$

Kombinasi 3 obat antihipertensi diberikan kepada pasien hipertensi di mana tekanan darahnya belum mencapai target ketika menggunakan terapi tunggal maupun kombinasi. ${ }^{9}$ Kombinasi 3 obat antihipertensi ini digunakan untuk memaksimalkan kemampuan menurunkan tekanan darah, meminimalkan efek samping obat, dan menjaga tekanan darah pasien dalam rentang normal sehingga tekanan darah tidak mudah berfluktuasi, sehingga berisiko 5 kali lebih tinggi terkena hipertensi. Dalam penelitian ini, kombinasi 3 obat antihipertensi terjadi pada 2 resep $(3,92 \%)$.

\section{Rasionalitas Penggunaan Obat Antihipertensi}

Evaluasi kerasionalan penggunaan obat antihipertensi dilakukan terhadap 51 data rekam medis pasien geriatri yang menderita hipertensi rawat jalan di RSUD Dr. H. Bob Bazar, SKM selama periode Januari-Juni 2019. Evaluasi kerasionalan dilakukan meliputi beberapa kriteria kerasionalan, yaitu tepat diagnosis, tepat indikasi, tepat obat, tepat dosis, tepat cara 
pemberian, tepat interval waktu pemberian dan tepat pasien. ${ }^{10}$

Penggunaan obat dikatakan rasional jika diberikan untuk diagnosia yang benar, jika diagnosia salah maka pemilihan obat terpaksa mengacu pada diagnosia yang salah tersebut. Pada Tabel 3 menunjukkan untuk tepat diagnosis yaitu sebesar $100 \%$ karena pada penelitian ini semua pasien geriatri di RSUD Dr. H. Bob Bazar, SKM memiliki tekanan darah $\geq 140 / 90-\geq 160 / 100$ mmHg. ${ }^{11}$ Evaluasi ketepatan indikasi merupakan proses penilaian pemilihan obat yang memenuhi kebutuhan pasien berdasarkan diagnosis yang dibuat karena alasan medis ${ }^{12}$. Dikatakan tepat indikasi ketika obat diberikan sesuai dengan gejala yang dirasakan pasien dan diagnosis yang ditegakkan serta manfaat terapeutik yang terbukti. Jika obat diberikan tanpa indikasi yang tepat, maka gejala dan penyakit pasien tidak akan hilang, karena obat memiliki rentang terapi yang spesifik dan berbeda. Data yang diperoleh menunjukkan bahwa dari 51 data rekam medis diperoleh hasil $100 \%$ tepat indikasi.

Evaluasi ketepatan obat berdasarkan Tabel 3, dari 51 data rekam medis diperoleh sebesar $100 \%$, di mana hasil penelitian ini dilihat dan dibandingkan dengan literatur yaitu JNC VIII berdasarkan diagnosis pasien dan obat yang diresepkan untuk pasien.

Evaluasi ketapatan dosis didasarkan pada resep obat antihipertensi yang berada dalam kisaran dosis minimum dan dosis harian yang direkomendasikan. Dosis dikatakan terlalu rendah atau kurang bila dosis yang diterima pasien berada di bawah kisaran dosis terapeutik yang seharusnya diterima pasien. ${ }^{13}$ Berdasarkan Tabel 3 menunjukkan bahwa dari 51 rekam medis, terdapat 48 data rekam medis yang menujukan tepat dosis, dan terdapat 3 data yang tidak tepat dosis. Hal ini disebabkan pada pemberian dosis propranolol terlalu rendah. Menurut literatur dosis yang direkomendasikan yaitu 40 mg 2 kali sehari. Kemudian pada pemberian dosis captropil terlalu rendah, dosis yang direkomendasikan adalah $25 \mathrm{mg}$ 2-3 kali sehari. Dosis yang terlalu rendah dapat menyebabkan kadar obat dalam darah turun di bawah kisaran terapeutik, sehingga tidak akan dapat memberikan respon yang diharapkan yaitu efek terapeutik dari penurunan tekanan darah tidak akan tercapai. Disisi lain, dosis obat yang terlalu tinggi dapat menyebabkan kadar obat dalam darah melebihi kisaran terapeutik, menyebabkan efek samping utama antihipertensi yaitu hipotensi dan kemungkinan efek toksik lainnya.

Evaluasi ketepatan cara pemberian obat didasarkan pada aturan pakai obat antihipertensi yang diresepkan untuk pasien dan harus mempertimbangkan keamanan dan kondisi pasien. Tabel 3 menunjukkan hasil cara pemberian obat yang tepat yaitu $100 \%$.

Evaluasi Interval pemberian obat dianggap tepat jika interval waktu antara konsumsi obat sesuai dengan waktu paruh obat dalam darah. Pada Tabel 3 tersebut menunjukkan hasil tepat interval waktu pemberian sebesar 96,08\%. Hal ini dikarenakan pada pemberian nifedipin sebanyak 8 jam sekali. Sedangkan berdasarkan literatur pemberian nifedipin sebaiknya dalam satu waktu (satu kali sehari). ${ }^{14}$

Evaluasi kerasionalan penggunaan obat berdasarkan penilaian kondisi pasien dikatakan tepat tanpa adanya efek samping maupun alergi atau kontraindikasi lain terhadap penggunaan obat untuk pasien geriatri secara individual. Evaluasi ketepatan pasien dalam penelitian ini dilakukan dengan membandingkan kontraindikasi obat yang diberikan dengan kondisi pasien pada catatan medik. ${ }^{15}$ Pada Tabel 3 menunjukkan hasil penggunaan obat berdasarkan tepat pasien sebanyak $100 \%$ karena semua obat yang diresepkan pada pasien hipertensi di RSUD Dr. H. Bob Bazar, SKM selama periode Januari - Juni 2019 sesuai dengan keadaan patologi dan fisiologi pasien serta tidak menimbulkan kontraindikasi pada pasien. Ketidaktepatan pasien mengakibatkan terjadinya efek samping yang tinggi pada keadaan fisiologis dan 
patologis pasien yang mengonsumsi obat. Hal ini juga dikarenakan pada penelitian ini hanya mengambil data pasien hipertensi tanpa diagnosis lain.

\section{KESIMPULAN}

Berdasarkan hasil penelitian yang telah dilakukan terhadap 51 pasien geriatri yang didiagnosis hipertensi di RSUD Dr. H. Bob Bazar, SKM selama periode Januari Juni 2019 dapat disimpulkan bahwa, evaluasi kerasionalan penggunaan obat antihipertensi dilihat berdasarkan kriteria tepat diagnosis sebesar $100 \%$, tepat indikasi sebesar 100\%, tepat obat sebesar $100 \%$, tepat dosis sebesar $94,12 \%$, tepat cara pemberian sebesar $100 \%$, tepat interval waktu pemberian sebesar $96,08 \%$, dan tepat pasien sebesar $100 \%$. Secara keseluruhan pengobatan yang memenuhi ketujuh kriteria penggunaan obat rasional adalah sebesar $96,8 \%$.

\section{UCAPAN TERIMA KASIH}

Peneliti mengucapkan terima kasih kepada pihak RSUD Dr. H. Bob Bazar, SKM yang telah membantu dan berpartisipasi dalam menyelesaikan penelitian ini.

\section{DAFTAR PUSTAKA}

1. Yosida I. Efektifitas Penggunaan Obat Antihipertensi Diinstalasi Rawat Inap. Skripsi. Yogyakarta: Universitas Sanata Dharma. 2016; Hal 1-4 dan 6-10.

2. Kemenkes, R. I. 2013. Riset Kesehatan Dasar; Riskesdas. Jakarta: Balitbang Kemenkes RI, 2013, 110-9.

3. Alaydrus $\mathrm{S}$, Toding N. Pola Penggunaan Obat Hipertensi Pada Pasien Geriatri Di Rumah Sakit Anutapura Palu Periode 08 Juli-08 Agustus 2019. Jurnal Mandala Pharmacon Indonesia. 2019; 5.02: 6573.

4. Riamah. Faktor-Faktor Penyebab Terjadinya Hipertensi Pada Lansia Di
UPT PSTW Khusnul

Khotimah. Menara Ilmu. 2019; 13.5.

5. Anggraini DA, Annes W, Eduward S, et al. Faktor-Faktor Yang Berhubungan Dengan Kejadian Hipertensi Pada Pasien Yang Berobat Di Poliklinik Dewasa Puskesamas Bangkinang Periode Januari Sampai Juni 2008. Skripsi. 2009. FK UNRI. Riau. hlm 18.

6. Susilo Y, Wulandari. Cara Jitu Mengatasi Hipertensi. 2012.

7. Dipiro J.T, Talbert R.L, Yee G.C, Matzke G.R, Wells B.G.P.L. Pharmacotherapy a pathophysiologi approach seventh edition, MC Graw Hill Companies, INC, United states of Amerika. 2008.

8. Florensia A. Evaluasi Penggunaan Obat Antihipirtensi di Instalasi Rawat Inap RSUD Kota Tangerang dengan Metode Anatomical Therapeutic Chemical/Defined Daily Dose Pada Tahun 2015. 2016.

9. Ardhany SD, Pandaran W; Pratama MRF. Profil Penggunaan Obat Antihipertensi Di RSUD Mas Amsyar Kasongan Kabupaten Katingan. Borneo Journal of Pharmacy. 2018;1(1) : 4750.

10. Kemenkes RI. Modul penggunaan obat rasional. Jakarta: Kementrian Kesehatan RI. 2011.

11. Eight Joint National Committee (JNC 8). Evidence-Based Guideline for the Management of High Blood Pressure in Adult. JAMA. 2014.

12. Untari EK, Agilina AR, Susanti R.. Evaluasi Rasionalitas Penggunaan obat Anti hipertensi di Puskesmas siantar hilir Kota Pontianak Tahun 2015. Pharmaceutical Sciences and Research. 2018; 5: 32-39.

13. Astuning AP \& Mutmainah N. Evaluasi Penggunaan Obat Antihipertensi Pada Pasien Dengan Hipertensi Komplikasi Di Rumah Sakit X Surakarta Tahun 2014. Universty Research Colloquium. 2016; 640 - 654. 
Herawati, dkk.

14. Br J Clin Pharmacol. British Journal of Clinical Pharmacology. 2004; 57(5): $632-639$.

15. Khotimah SEYN \& Musnelina L. Evaluasi Penggunaan Obat Antihipertensi Pada Pasien Hipertensi Primer Usia $\leq 45$ Tahun Di Instalasi Rawat Jalan Rumah Sakit Umum Daerah (RSUD) Kota Depok. Sainstech Farma. 2016; 9.1 
Evaluasi Rasionalitas Penggunaan Antihipertensi pada Pasien Geriatri di RSUD Dr. H Bob Bazar, SKM Lampung Selatan 